\title{
What determines flood risk perception? A review of factors of flood risk perception and relations between its basic elements
}

\author{
Ewa Lechowska ${ }^{1}$
}

Received: 19 June 2018/Accepted: 10 September 2018/Published online: 25 September 2018

(C) The Author(s) 2018

\begin{abstract}
While the methods of risk analysis are generally based on objective measurements, the subjective assessment of risk, such as risk perception, is currently considered a crucial aspect in the context of flood risk management. Risk perception is regarded as an assessment of the perceived probability of hazard and the perceived probability of the results (most often-negative consequences). The work attempts to answer the question: What determines flood risk perception? The knowledge of the factors influencing flood risk perception can solve the issue of the society's underestimation of flood risk. This issue was considered both in terms of the impact of particular factors on flood risk perception and the interrelationship between three characteristics of flood risk perception: preparedness, worry and awareness. The results were developed based on critical analysis of the empirical research. The review shows that the way particular characteristics determine flood risk perception is not clear and many authors show the diverse conclusions from the similar research. Taking into account various research results, the following factors were distinguished: primary (which clearly influence risk perception), secondary (which influence it unclearly and require further research) and intervening (often describing the context). The organization of the results of the research on the flood risk assessment conducted herein aims to improve the understanding of the human perception of flood risk and, as a result, will lead to the decrease in flood risk by improving the communication of the issue and motivating the residents of the endangered areas to take actions that reduce the negative effects of floods.
\end{abstract}

Keywords Risk perception · Floods · Factors $\cdot$ Review

Ewa Lechowska

ewaglo@amu.edu.pl

1 Department of Spatial Management, Faculty of Geographical and Geological Sciences, Institute of Socio-Economic Geography and Spatial Management, Adam Mickiewicz University, B. Krygowskiego 10, 61-680 Poznan, Poland 


\section{Introduction}

The research on risk perception is mainly the domain of sociological sciences but it also perfectly fits issues in human geography or socio-economic geography, which emphasise not only a sociological aspect of the phenomenon but its economic and spatial dimensions as well. Without any knowledge of local or regional conditions, the possibilities to learn about risk perception are reduced, whereas the research results may lead to totally contradictory conclusions.

Floods represent about one-third of all natural disasters (UNISDR 2005). Together with storms they comprise $77 \%$ of economic losses caused by extreme weather events from 1980 to 2006 in Europe (CEA 2007).

Risk perception is defined as an assessment of the probability of hazard and the probability of the results (most often-the negative consequences) perceived by the society (Bubeck et al. 2012; Becker et al. 2013; Grothmann and Reusswig 2006). Kellens et al. (2011) consider the study of flood risk perception as a research on human consciousness, emotions and behaviours with regard to hazards. According to Bubeck et al. (2012), the majority of the reviewed studies present the assessment of risk perception only with regards to the probability of a flood occurrence (see: Kreibich et al. 2005; Takao et al. 2004; Thieken et al. 2007; Miceli et al. 2008; Lindell and Hwang 2008). Raaijmakers et al. (2008) specify the definition of flood risk perception as a combination of three specific factors of risk-awareness, worry and preparedness.

While the methods of risk analysis are usually based on objective measures, the subjective risk assessment, such as risk perception is currently considered a crucial aspect in the context of flood risk management (Kellens et al. 2011). The necessity to take flood risk perception into account while conducting flood risk management is commonly emphasised as part of the social context (Renn 2005; Brown and Damery 2002). It is crucial, as it determines the attitude (the level of preparation for a flood) and the possible behaviour of the residents of floodlands when faced with a flood. Knowledge of public risk perception is meant to assure an improvement in the effectiveness of flood risk management (Kellens et al. 2011). Understanding how society perceives flood risk is of crucial importance in determining a fitting method of spreading information about the flooding, meant to increase the society's trust in its government and will lead to greater capability to react to floods as well as increase social resilience (Bradford et al. 2012). According to Bradford et al. (2012), the public perception of risk must be in the centre of attention, because the authorities' lack of understanding the society is the reason for failure in the politics of flood risk management.

In fact, perception (the level of a flood risk perceived by the society) often does not coincide with the flood risk level determined by the experts (see Duží et al. 2014; Działek et al. 2013b; Ceobanu and Grozavu 2009; Heijmans 2001). They tend to perceive flood risk more realistically than the whole of society (Krasovskaia et al. 2001). People underestimating the flood risk are a major problem and a challenge in managing it. Knowledge of the factors influencing the subjective flood risk perception can solve this problem and lead to a decrease in the flood risk by motivating the residents of endangered areas to take actions that mitigate negative effects of floods (cf. Becker et al. 2013). When faced with diverse perceptions of the flood risk, it is necessary to know the factors influencing flood risk perception. That would allow developing a strategy for communicating the danger that would increase the communities' resistance to a flood hazard (Bradford et al. 2012). 
Messner and Meyer (2006) claim that the process of communication regarding flood risk and its perception should be promoted as a foundation of politics of flood risk management.

Over the last 20 years seven review studies on flood risk perception have been published (i.e. Boholm 1998; Bradford et al. 2012; Bubeck et al. 2012; Wachinger et al. 2013; Kellens et al. 2013; Birkholz et al. 2014; Raska 2015). Boholm's work (1998) does not deal with flood risk factors but compares the transnational research results of the assessment of the qualitative features of the risk concerning natural, technological, nuclear and other disasters (flooding included) conducted in 1978-1997. The paper of Bradford et al. (2012) is not exactly a study review, but it touches upon mutual dependencies between preparedness, worry and awareness based on the research conducted under two strictly determined projects embracing 6 European countries. It includes only demographic factors of flood risk perception and the spatial scope of analyses is strictly limited. Bubeck et al. (2012) deal only with part of the issue depicted in this work, i.e. they describe factors influencing preparedness. In turn, the review of Wachinger et al. (2013) focuses on just two factors of risk perception of natural hazards (experience, trust in authorities and experts). The review of selected factors influencing flood risk perception and preparedness was short and conducted only marginally in the work of Kellens et al. (2013). It was not its main aim. Birkholz et al. (2014) do not describe in any way flood risk factors, but focuses on the explanation of the basic constructs applied to understand flood risk perception. Raska (2015) limited the review of factors that determine flood risk perception to East-Central Europe only. On the one hand, he concentrates on post-communist countries and indicates certain regularities. On the other hand, because of the territorial limitation, he did not include many other valuable empirical works. Hence, the existing reviews did not attempt to comprehensively describe the factors of flood risk perception on the basis of the results of empirical studies. As the research on the flood risk is socially significant, an overview of the current knowledge in this field is considered necessary.

The article aims to prepare a list of factors considered in research on flood risk perception and classify them by the nature and type of influence on flood risk perception and then formulate recommendations regarding further research in this area, based on the empirical research analysis. The nature of a factor results from the kind of life of persons investigated and the analysed features of individuals. When it comes to the type of the influence of the factor on flood risk perception, it has been found to be either clear or unclear or maybe even excluded, based on the research results described in the literature.

Numerous studies regarding the analysis of flood risk perception have been conducted. The works mostly regard the relations between the three basic elements which characterise flood risk-awareness, worry and preparedness (listed by Raaijmakers et al. 2008), as well as the factors that influence them.

Interestingly, the results of the studies on flood risk perception conducted so far are often contradictory and, therefore, should be systematized. Boholm himself (1998, p. 153), in one of his works devoted to the review of comparative research on risk perception drew the conclusion that "we should be systematizing results" which are often contrasting. That was accomplished in this article and constitutes the original contribution of this work. The arrangement of the relations between various elements of the risk and potential factors influencing its perception presented herein will improve the understanding of human perception of flood risk and, as a result, will lead to the improvement in communicating the risk and decreasing it.

The work is divided into seven main parts, of which the first one is introductory in character and describes the paper structure. The second contains the applied method of a literature review and the characteristics of the collected works. The third part shows the 
fundamental division of flood risk perception factors, and the fourth, most extensive, directly refers to the issue in question. This part of work presents the factors influencing individual elements which characterise flood risk perception (i.e. awareness, worry, preparedness); then, the factors that generally impact flood risk perception were detailed and the interrelations between the above-mentioned characteristics of risk and the general perception of flood risk were described. This pattern/order of reviewing the factors arises from the research methods presented in literature, since some studies focused only on the analysis of a single risk characteristic out of the three or analysed each characteristic separately, while others referred to the perception of risk as a whole. The next chapter involves the division of factors according to the character and type of influence on flood risk perception. Two last parts comprise the conclusions and recommendations for further research.

\section{Methods}

The research on flood risk perception is highly productive. It is a dynamic field of an empirical investigation which cannot be examined thoroughly and constitutes a large output that should be used at least in flood risk management.

A systematic review was conducted in three stages. The Google Scholar, Web of Science/ Knowledge and Scopus databases were searched for appropriate research works via the following keywords: flood risk perception, risk perception, flood, factors, awareness, worry and preparedness, trust, fear, emotion, denial, risk underestimation, action, attitude, disasters, vulnerability, resilience. The above-mentioned electronic databases include numerous published research works in a variety of fields. Account has been taken of works published over the last 20 years in order to detect contemporary trends in research on flood risk perception. Afterwards, the abstracts, introductions, discussions and conclusions of the selected works were reviewed. That enabled the preparation of an initial list of factors that could potentially influence flood risk perception and its basic characteristics. Finally, if the analysed above sections of an article were closely related to the subject of the notion of interest, the (whole) article was studied in-depth. Moreover, if the given article referred to any other work directly related to the issues raised, the latter was also reviewed in the same manner. The above constituted the procedure of isolating relevant information and data from the available documents. The selection of research was made with a "snowballing" strategy.

As a result, 50 empirical studies were overviewed, which mainly focused on the simple purpose of determining the level of flood risk perception in a given community and analysed it in relation to the factors previously specified on the basis of the literature review or resulting from the research objective (Table 1).

The collected empirical studies on flood risk perception primarily represent a psychometric approach. They seek to describe the social phenomenon in a statistical manner. Psychometric studies consist in a quantitative analysis of individual risk perception (Fischhoff et al. 1978; De Marchi 2007). They assume the existence of cognitive patterns thanks to which the investigated phenomena can be modelled (Kellens et al. 2013). As a result, the factor in this work is mainly understood as an independent variable considered in modelling a social phenomenon such as flood risk perception. ${ }^{1}$ The selected research is rather exploratory than theoretical.

\footnotetext{
${ }^{1}$ It should be noted, however, that in the analysed works methods determining mutual dependence between variables were sometimes used (e.g. a correlation coefficient). In such a case it was herein assumed that this co-dependence (covariance) would be treated as a one-way dependence.
} 
Table 1 Flood risk perception factors in the empirical research

\begin{tabular}{|c|c|c|}
\hline Factors & Empirical papers & \\
\hline \multirow[t]{6}{*}{ Individual's physical location } & Miceli et al. (2008) & Duží et al. (2014) \\
\hline & Botzen et al. (2009a) & Oasim et al. (2015) \\
\hline & Botzen et al. (2009b) & O’Neill et al. (2016) \\
\hline & Zhang et al. (2010) & Bustillos Ardaya et al. (2007) \\
\hline & Kellens et al. (2011) & Bera and Danek (2018) \\
\hline & Ludy and Kondolf (2012) & \\
\hline Flood characteristics & Ho et al. (2008) & \\
\hline \multirow[t]{7}{*}{ Residence characteristics } & Takao et al. (2004) & Działek et al. (2013a) \\
\hline & $\begin{array}{l}\text { Grothmann and Reusswig } \\
\text { (2006) }\end{array}$ & Działek et al. (2013b) \\
\hline & Lindell and Hwang (2008) & Oasim et al. (2015) \\
\hline & Biernacki et al. (2009) & Stojanov et al. (2015) \\
\hline & Armas and Avram (2009) & Koks et al. (2015) \\
\hline & Hung (2009) & Thistlethwaite et al. (2018) \\
\hline & Kellens et al. (2011) & \\
\hline \multirow[t]{4}{*}{ Size of consequences } & Takao et al. (2004) & Miceli et al. (2008) \\
\hline & $\begin{array}{l}\text { Grothmann and Reusswig } \\
\text { (2006) }\end{array}$ & Ho et al. (2008) \\
\hline & Raaijmakers et al. (2008) & Biernacki et al. (2009) \\
\hline & Siegrist and Gutscher (2008) & Stojanov et al. (2015) \\
\hline \multirow[t]{2}{*}{ Range of impact } & Sjöberg (1998) & Thistlethwaite et al. (2018) \\
\hline & Miceli et al. (2008) & Bera and Danek (2018) \\
\hline \multirow[t]{15}{*}{ Direct experience } & Barnett and Breakwell (2001) & Kellens et al. (2011) \\
\hline & Baan and Klijn (2004) & Kreibich et al. (2011) \\
\hline & Kreibich et al. (2005) & Pagneux et al. (2011) \\
\hline & $\begin{array}{l}\text { Grothmann and Reusswig } \\
\text { (2006) }\end{array}$ & Terpstra (2011) \\
\hline & Thieken et al. (2007) & $\begin{array}{l}\text { Botzen and van den Bergh } \\
\text { (2012) }\end{array}$ \\
\hline & Siegrist and Gutscher (2008) & Ludy and Kondolf (2012) \\
\hline & Lindell and Hwang (2008) & Duží et al. (2014) \\
\hline & Miceli et al. (2008) & Oasim et al. (2015) \\
\hline & Burningham et al. (2008) & Stojanov et al. (2015) \\
\hline & Biernacki et al. (2009) & Armas et al. (2015) \\
\hline & Armas and Avram (2009) & Comănescu and Nedelea (2016) \\
\hline & Botzen et al. (2009a) & Bustillos Ardaya et al. (2007) \\
\hline & Zaalberg et al. (2009) & Thistlethwaite et al. (2018) \\
\hline & Terpstra et el. (2009) & Bera and Danek (2018) \\
\hline & Terpstra (2009) & \\
\hline
\end{tabular}


Table 1 continued

\begin{tabular}{|c|c|c|}
\hline Factors & Empirical papers & \\
\hline \multirow{13}{*}{$\begin{array}{l}\text { Socio-economic and demographic } \\
\text { profiles }\end{array}$} & Sjöberg (1998) & Hung (2009) \\
\hline & Cutter et al. (2003) & Kellens et al. (2011) \\
\hline & Baan and Klijn (2004) & Scheuer et al. (2011) \\
\hline & $\begin{array}{l}\text { Grothmann and Reusswig } \\
\text { (2006) }\end{array}$ & $\begin{array}{l}\text { Botzen and van den Bergh } \\
\text { (2012) }\end{array}$ \\
\hline & Knocke and Kolivras (2007) & Ludy and Kondolf (2012) \\
\hline & Siegrist and Gutscher (2008) & Poussin et al. (2014) \\
\hline & Lindell and Hwang (2008) & Duží et al. (2014) \\
\hline & Miceli et al. (2008) & Oasim et al. (2015) \\
\hline & Burningham et al. (2008) & Stojanov et al. (2015) \\
\hline & Armas and Avram (2009) & Koks et al. (2015) \\
\hline & Botzen et al. (2009a) & Bustillos Ardaya et al. (2007) \\
\hline & Zaalberg et al. (2009) & Thistlethwaite et al. (2018) \\
\hline & Terpstra (2009) & Bera and Danek (2018) \\
\hline \multirow[t]{9}{*}{ Information (knowledge) } & King (2000) & Heitz et al. 2009 \\
\hline & Thieken et al. (2007) & $\begin{array}{l}\text { Botzen and van den Bergh } \\
\text { (2012) }\end{array}$ \\
\hline & Raaijmakers et al. (2008) & $\begin{array}{l}\text { Bichard and Kazmierczak } \\
\text { (2012) }\end{array}$ \\
\hline & Siegrist and Gutscher (2008) & Działek et al. (2013a) \\
\hline & Lindell and Hwang (2008) & Działek et al. (2013b) \\
\hline & Miceli et al. (2008) & Duží et al. (2014) \\
\hline & Biernacki et al. (2009) & Armas et al. (2015) \\
\hline & Botzen et al. (2009a) & Comănescu and Nedelea (2016) \\
\hline & Botzen et al. (2009b) & Bustillos Ardaya et al. (2007) \\
\hline \multirow[t]{3}{*}{ Indirect experience } & Cutter et al. (2003) & Działek et al. (2013a) \\
\hline & Biernacki et al. (2009) & Działek et al. (2013b) \\
\hline & Terpstra et al. (2009) & Bustillos Ardaya et al. (2007) \\
\hline \multirow[t]{2}{*}{ Cultural-historical context } & Działek et al. (2013a) & Armas et al. (2015) \\
\hline & Działek et al. (2013b) & \\
\hline Religious context & Schmuck (2000) & \\
\hline \multirow[t]{4}{*}{ Political context } & $\begin{array}{l}\text { Grothmann and Reusswig } \\
\text { (2006) }\end{array}$ & Hung (2009) \\
\hline & Terpstra and Gutteling (2008) & Heitz et al. 2009 \\
\hline & Terpstra et el. (2009) & Terpstra (2011) \\
\hline & Terpstra (2009) & $\begin{array}{l}\text { Bichard and Kazmierczak } \\
\text { (2012) }\end{array}$ \\
\hline
\end{tabular}

Various research methods, often related to the chosen research purpose, were used to asses flood risk perception in the selected works. They included: a telephone survey (Becker et al. 2013; Grothmann and Reusswig 2006; Działek et al. 2014), structured telephone interviews (Działek et al. 2013b), in-depth interviews (Działek et al. 2014), a questionnaire survey (Armas and Avram 2009; Kellens et al. 2011; Raaijmakers et al. 2008), “door-to-door" interviews/questionnaire (Duží et al. 2014; Stojanov et al. 2015), 
semi-structured interviews (Fitton et al. 2015; Bustillos Ardaya et al. 2007), personal handover (Pagneux et al. 2011; Kellens et al. 2011; Bradford et al. 2012; Werritty et al. 2007), post boxes (Kellens et al. 2011; Bradford et al. 2012; Werritty et al. 2007), via local schools (Działek et al. 2014), focus groups (Działek et al. 2013b; Werritty et al. 2007), online surveys (Bradford et al. 2012). Also there were many sampling methods used in those studies including random sampling (Armas and Avram 2009), accidental sampling (Pagneux et al. 2011) and snowball sampling (Fitton et al. 2015). It should be emphasised that the questions about the perception of flood risk were formed in a different way, either as closed or open-ended questions. It also needs to be emphasised that diverse statistical methods to estimate the impact of particular factors on flood risk perception and to find relations between awareness, worry and preparedness were applied. In most cases those were: correlation analysis (Kellens et al. 2011; Kreibich et al. 2005; Lindell and Hwang 2008; Miceli et al. 2008; Takao et al. 2004; Thieken et al. 2006, 2007; Grothmann and Reusswig 2006; Knocke and Kolivras 2007; Miceli et al. 2008), a Chi squared test (Werritty et al. 2007; Bradford et al. 2012), independent samples t-tests (Bradford et al. 2012), one-way analysis of variance ANOVA (Armas and Avram 2009; Bradford et al. 2012; Pagneux et al. 2011), regression analysis (Kellens et al. 2011; Duží et al. 2014; Lindell and Hwang 2008; Siegrist and Gutscher 2006; Grothmann and Reusswig 2006; Miceli et al. 2008; Stojanov et al. 2015). They were also conducted at different times from the last flood, or from the last improvements in flood protection. Questionnaire surveys were carried out among people of different cultures and histories living in different countries (in Europe, Asia, America) close to rivers with different regimes.

\section{Factors of flood risk perception}

Literature distinguishes numerous factors generally influencing the perception of flood risk or its individual elements. Tobin and Montz (1997) divide factors influencing the perception of risk and its main elements (awareness, worry, preparedness) into two groups: situational and cognitive ones. The former include:

- the physical location reflecting proximity to a hazard (the probability of the occurrence of flood);

- the nature of the flood (since a violent mountain flood is perceived differently to a lowland flood that is long-term in nature and can be predicted beforehand);

- the extent of the effects;

- the experience;

- the level of hazard awareness and the degree of its uncertainty;

- socio-economic and demographic factors of the population (gender, age, education, income, number of children);

- the residence characteristics (owning a house, type of a building, presence of a ground floor, cellar);

- the cultural-historical context;

- voluntary/involuntary nature;

- the group of people influenced by the flood (individuals can perceive a risk differently, depending on whether they are directly influenced themselves, their families are influenced or it regards people they are not connected to emotionally).

The cognitive factors reflect the personal and psychological elements of an individual and comprise emotional and behavioural attributes which constitute single emotions caused by 
the flood and the tendencies to act in a specific way due to the flood (Tobin and Montz 1997; Bradford et al. 2012).

Wachinger et al. (2013) suggest some other division of flood risk perception in their literature review in which four groups of factors responsible for determining risk perception and natural hazards: (1) Risk factors (scientific characteristics of a risk, perceived probability of the occurrence), (2) Informational factors (the source and level of information), (3) Personal factors (gender, age, education, occupation, personal knowledge, personal disaster experience, trust in authorities, trust in experts, confidence in different risk reduction measures, world views and religiousness), (4) Contextual factors (economic factors, vulnerability indices, home ownership, family status, country, area of living, closeness to the waterfront, size of community, age of the youngest child).

In turn, Boholm (1998) and Birkholz et al. (2014) in their reviews use the term 'contextual factors', referring to: gender, social marginalization, education and occupation or structural constraints and the political/economic forces. The first relate to social background factors, the second influence the access to resources and a various degree of susceptibility of marginalized groups to hazards.

In their work, O'Neill et al. (2016) use the terms of cognitive or behavioural, socioeconomic and geographical factors. When discussing cognitive or behavioural factors they meant a direct experience of flood and losses, emotional and affective reactions, fear, worry. Among socio-economic factors they mention age, gender, civil status, education, income and holding of a building. A geographical factor in this work is distance or proximity to a hazard.

It is not surprising that in the studies of risk perception, experience is most often firstly taken into account, then social, economic and demographic factors (Table 1).

\section{Relations between preparedness, worry and awareness and their factors}

\subsection{Awareness and worry and their factors}

Being aware of the risk is connected to a person knowing that he or she resides or is located in the area of the flood risk. Therefore, it appears obvious that information sharing and the education of society increase awareness (Raaijmakers et al. 2008; King 2000). According to Shen (2009), the awareness of the risk decreases when there is little information provided. Moreover, even experiencing a flood by itself increases a person's awareness. Thus, the access to information significantly influences the awareness of living in a hazard area. Lindell and Hwang (2008) have proved empirically that people who experienced this disaster were much more aware than people not familiar with it. Therefore, awareness rises together with the experience of flood, which was confirmed by the research of Bradford et al. (2012). It needs to be emphasised that the level of risk awareness is also connected to demographic factors (Bradford et al. 2012). Biernacki et al. (2009) claim that raising awareness of danger among inhabitants is very difficult, especially in areas where disasters occur rarely. Attention is paid to the influence of the dread and the unknown on risk perception. In the opinion of Kraus and Slovic (1988), the higher the level of the dread and the unknown, the higher the risk perceived (Table 2).

The influence of experience on the feeling of worry is unambiguous. The occurrence of flooding itself increases the level of worries. It is additionally multiplied by the losses suffered due to the flooding. According to Jaracz (2001), the society is more susceptible to 
the extent of potential losses than to the level of probability of the flood risk. Therefore, it happens that in a high-risk area where there has been no flooding in the recent years the level of worry is low (Biernacki et al. 2009). Depending on the expected severity of flood effects, the level of worries of endangered individuals can vary (Raaijmakers et al. 2008). People usually assume that the size of future floods will be similar to those experienced earlier (Burn 1999; Howe 2011). Research has shown a dependency between peoples' education and the level of worry-those having lower education worry more about flooding (Bradford et al. 2012; Sjöberg 1998). Taking into consideration that there is a relationship between education and the level of income, one can infer that those with higher income worry less about the consequences of flood. Although they can suffer greater financial losses, they are better protected by insurances and they find it easier to replace lost property and reduce flood effects (Bradford et al. 2012). In literature, it is often suggested that women are more prone to worrying about risks (e.g. Sjöberg 1998; Poortinga et al. 2011). However, the studies of Bradford et al. (2012) have not shown a strong relationship between the sense of unease and gender (Table 2).

\subsection{Preparedness and its factors}

Preparedness concerns not only the preparatory actions before the flood, the application of mitigating means and the capacity of coping with flood, but also the possibility of recovery afterwards (Raaijmakers et al. 2008; van der Veen and Logtmeijer 2005).

Recently, more and more empirical research has focused on the analysis of factors driving the private mitigating behaviours. However, they bring divergent results. For example, the research results concerning the influence of experience and knowledge

Table 2 Impact of potential factors on basic elements of risk perception presented in literature

\begin{tabular}{|c|c|c|c|c|}
\hline Factors & Worry & Awareness & Preparedness & Perception (in general) \\
\hline Location (hazard) & & & \pm & \pm \\
\hline Hazard proximity & & & - & \pm \\
\hline Living on ground floor & & & + & - \\
\hline Length of residence & & & + & + \\
\hline Direct experience & + & + & \pm & + \\
\hline Age & & - & \pm & \pm \\
\hline Gender & \pm & - & + & \pm \\
\hline Education & + & - & - & \pm \\
\hline Incomes & & - & \pm & - \\
\hline Household size (children) & & & + & - \\
\hline Home ownership & & & + & \pm \\
\hline Cellar ownership & & & + & - \\
\hline Knowledge & & + & \pm & + \\
\hline Indirect experience & & & + & + \\
\hline Cultural-historical context & & & + & + \\
\hline Religious context & & & + & + \\
\hline Political context & & & + & + \\
\hline
\end{tabular}

Explanations: "+" clear relation, " \pm " unclear relation, "_" no relation 
(information) on the level of preparedness are contradictory. On the one hand, the literature confirms the positive relationship between previous experiences of flooding and the level of the application of individual mitigating means (Grothmann and Reusswig 2006; Takao et al. 2004; Biernacki et al. 2009; Siegrist and Gutscher 2008; Lamond et al. 2009; Slovic et al. 2004; Terpstra 2011; Kreibich et al. 2011; Stojanov et al. 2015; Thistlethwaite et al. 2018). On the other hand, the correlation and regression values indicated are often low or medium (Grothmann and Reusswig 2006; Siegrist and Gutscher 2006; Thieken et al. 2007; Miceli et al. 2008; Lindell and Hwang 2008). According to Duží et al. (2014), it is hard to claim that floods inevitably influence the selection of family mitigating means. Their studies and the research of Takao et al. (2004) and Thieken et al. (2007) have shown no such dependency (Table 2).

Another view claims that reactions to risk situations may differ depending on individual experiences (Lewis et al. 2011). The studies of Stojanov et al. (2015) show that the size of damages incurred positively influences the number of protective measures undertaken before the flood. Furthermore, the experience to date appears to be crucial in the process of learning how to behave during floods (Heijmans 2001, Miceli et al. 2008; Pagneux et al. 2011). In terms of knowledge about the hazard and its influence on preparedness, Botzen et al. (2009a) observe a negative relationship between people's knowledge about floods and their readiness to invest in preventive measures. Lindell and Hwang (2008) also claim that there is a direct influence of the information sources on the mitigating behaviours of people at risk of flooding. However, there are also studies according to which an increase in knowledge and information does not correlate positively with safety precautions (Thieken et al. 2007; Miceli et al. 2008), in fact, there is no relation between these two factors at all (Siegrist and Gutscher 2008). This diversity of research results suggests that knowledge is not always a useful indicator of behaviours mitigating floods (Bubeck et al. 2012). The obtained results regarding the relation between the location in separate flood risk zones and steps taken to reduce the danger were unclear. The research of Duží et al. (2014) indicates that with an increase in the hazard level (the location of a household in the zone of higher probability of flooding), the measures reducing the risks are applied more often. Kunreuther (1996), on the other hand, suggests that people living in highest-risk areas rarely take measures voluntarily to reduce the effects of flooding, which makes them more susceptible to catastrophic occurrences (Table 2).

The studies presented in the literature suggest that preparedness for natural disasters and preventive measures are often related to numerous social and economic factors (Miceli et al. 2008). The relationship between gender and having children is clear-more men and households with children take preventive measures (Duží et al. 2014; Stojanov et al. 2015). The differences between genders in terms of perceiving the level of preparedness may reflect a higher level of men's trust in their own capabilities to take preventive actions (Miceli et al. 2008). Numerous studies have shown a small or non-existent influence of education on precautionary behaviours (Grothmann and Reusswig 2006; Lindell and Hwang 2008; Zaalberg et al. 2009; Knocke and Kolivras 2007; Botzen and van den Bergh 2012). In turn, the income level and age can affect the preparedness in various ways. Some claim that older residents of floodlands more often take precautionary measures than younger ones (Działek et al. 2013a; Grothmann and Reusswig 2006), while others see poor or no correlation between the age and being cautious (Lindell and Hwang 2008; Knocke and Kolivras 2007; Botzen and van den Bergh 2012; Zaalberg et al. 2009). The same is true with regards to the influence of income on taking individual protective measures - it is unclear. On the one hand, according to Grothmann and Reusswig (2006), Stojanov et al. (2015) and Thistlethwaite et al. (2018), income largely correlates with taking mitigating 
measures. People with higher incomes are more prone to investing in the means alleviating flood effects. Still, the relationship between income and the demand for mitigating measures is not significant in the studies of Botzen et al. (2009a), Lindell and Hwang (2008) and Zaalberg et al. (2009). The last researchers correctly observed that social and economic variables alone are not able to account for precautionary behaviour in the face of flooding (Table 2).

Furthermore, Grothmann and Reusswig (2006), Harries and Penning-Rowsell (2011) and Thistlethwaite et al. (2018) have shown a positive influence of owning a house on taking mitigating steps. When it comes to preventive measures, the type of buildings and, consequently, the size of a town are important. Villagers usually living in detached singlefamily houses are more at risk of natural disasters (especially flooding) than residents of towns or cities (Biernacki et al. 2009). On the other hand, in larger cities where the majority of population resides in multi-family blocks of flats some protective measures are downright impossible (Działek et al. 2013a, b). Therefore, there is a large diversity between the residents of villages and cities or towns, since in the latter the activity in applying precautionary measures is much smaller. With an increase in the size of towns, the percentage of residents protecting their households from floods decreases. It does not mean that preparation is worse. It simply stems from the limited possibilities of protecting multi-family buildings predominating in cities (Biernacki et al. 2009). What is more, the distance to the hazard (river) appears to have small influence on mitigating behaviours (Miceli et al. 2008; Lindell and Hwang 2008; Botzen et al. 2009a) (Table 2).

\subsection{Flood risk perception and its factors}

Empirical studies unambiguously indicate that knowledge influences risk perception. According to Biernacki et al. (2009), the perception of dangers and natural disaster is based on knowledge, which, in turn, is based on the previously gained information. Wachinger et al. (2013) hold that information broadcast by media shape risk perception to a certain degree. Messner and Meyer (2006) claim that assessments of risk levels differ due to varying levels of information and uncertainty. Those having little knowledge about the causes of floods have lower risk perception (Botzen et al. 2009a; Raaijmakers et al. 2008; Działek et al. 2013b). According to Raaijmakers et al. (2008), providing the public with information about the flood risk usually increases its perception. Ristic et al. (2012) correctly notice that the lack of a representative flood database causes the emergence of an incorrect risk perception. Interestingly, the research of Siegrist and Gutscher (2006) shows that many respondents are unaware of the existence of flood risk maps, which proves that people assess the risk of flooding on the basis of experience and the knowledge acquired from a local instead of the documented calculations (Duží et al. 2014) (Table 2).

Numerous studies emphasise the role of one's own experiences in shaping flood risk perception (Heijmans 2001; Grothmann and Reusswig 2006; Siegrist and Gutscher 2006; Kreibich et al. 2005; Kellens et al. 2011; Duží et al. 2014; Barnett and Breakwell 2001; Botzen et al. 2009a; Armas and Avram 2009; Zaalberg et al. 2009; Slovic et al. 2004; Bustillos Ardaya et al. 2007). People with a direct experience display a higher level of flood risk perception (Kellens et al. 2011; Oasim et al. 2015; Thistlethwaite et al. 2018). In other words, in the areas rarely plagued by floods social risk perception is usually low (Bradford et al. 2012; Messner and Meyer 2006; Lamond et al. 2009) (Table 2).

Yet, people's attitudes, especially towards incidental phenomena, change with time (Comănescu and Nedelea 2016). Usually the sense of danger decreases shortly after the 
given phenomenon (Biernacki et al. 2009). Therefore, society tends to forget about the risk associated with rare occurrences, such as floods (Raaijmakers et al. 2008; Biernacki et al. 2009; Colten and Sumpter 2009). According to The International Commission for the Protection of the Rhine (ICPR), flood risk perception usually decreases 7 years after flooding while catastrophic disasters are remembered much longer (ICPR 2002). The literature also suggests that the positive influence of experiences on private mitigating behaviours may disappear several years after the flood (Terpstra 2011). Hence, the time of the previous flood (time of the experience) plays a major role, since it can be expected that the experience of the flood that occurred a long time ago has little influence on current risk perception and mitigating behaviours (Grothmann and Reusswig 2006). Long floodless periods result in a decrease in the level of worry and awareness (Raaijmakers et al. 2008; Bradford et al. 2012) (Table 2).

Risk perception can also be strengthened or weakened by an indirect experience. In this respect, communication networks in the form of media and personal interactions with people play a major role (Wachinger et al. 2013). In the research of Biernacki et al. (2009) the most often mentioned source of information on natural disasters and extreme phenomena was mass media. In terms of accessibility heuristics (depicting the cognitive scheme serving information processing referring to the facts people remember and not to actual events), attention is paid to the moderating functions of indirect experience (communication channels, especially media reports), which can modify, enhance or weaken the risk assessment (Boholm 1998; Morgan et al. 2001). In turn, in studies on affect heuristics, emphasis is put on the notion that judgements and reactions of people (risk perception) are influenced by emotions and can be manipulated, e.g. by advertisements (Slovic et al. 2004). In current works on flood risk perception, the role of media in it is not considered. The earlier studies (before 1998) addressed this problem directly and more widely, i.e. relating to all potential hazards (technological, social, natural). They prove that media coverage can contribute to a biased risk assessment, on the one hand emphasising dramatic and catastrophic events and neglecting everyday hazards on the other (Johnson and Tversky 1983; Short 1984). Sjöberg (1996) are of the opinion that relation between media and risk perception is complex and it cannot be just assumed that media are a constant go-between in all societies. The role of media in society and their various aims in different political and economic systems should be taken into account. For example, the work of Englander et al. (1986) proved that in communist countries media were controlled more by the government in comparison to democratic states; therefore they do not fully inform about hazards and diminish risk perception. Media coverage contributes to risk perception especially when recipients do not have personal experience connected with a risk (Wachinger et al. 2013). Moreover, the analysed papers emphasise that the capability of people to acquire information and to evoke experience depends largely on social structures and the type of social capital. In societies with bonding social capital characterised by strong social bonds (villages and small towns) an increase in the importance of spreading information about local dangers between generations among the residents can be observed (Działek et al. $2013 \mathrm{a}, \mathrm{b})$. In the case of bridging social capital with weak social bonds the flow of information is hindered. These are, for example, cities where the populations are more mobile and people have limited access to information (Działek et al. 2013a, b; Cutter et al. 2003). In the opinion of Terpstra et al. (2009) other people's experiences regarding social communication (that is hearing or reading about the effects of dangers influencing friends, relatives, neighbours) influence less individual risk perception than personal experiences. The studies of Bustillos Ardaya et al. (2007) indicate that local impact and information 
provided by neighbours, family and friends are more important in forming risk perception than institutional influence (Table 2).

Individual social and demographic features may play a major role in shaping the perception of natural disasters (Chauvin et al. 2007; Botzen et al. 2009a; Armas and Avram 2009; Zaalberg et al. 2009; Peacock et al. 2005). The research of Kellens et al. (2011) explicitly indicates that older people usually have higher flood risk perception. The situation is similar with women. Therefore, age and gender are the features determining risk perception, which is consistent with the results of the research of Lindell and Hwang (2008) as well as Bustillos Ardaya et al. (2007). However, there are also studies proving that age does not influence significantly flood risk perception (Oasim et al. 2015; Armas et al. 2015), income (Oasim et al. 2015; Botzen et al. 2009a) and the size of a household (Oasim et al. 2015; Kreibich et al. 2005; Zaalberg et al. 2009) alike. According to Kellens et al. (2011) and Armas et al. (2015), education has no influence on the level of the risk perceived. On the other hand, the research of Oasim et al. (2015) and Botzen et al. (2009a) proves positive correlation between the level of education and flood risk perception indicating that education makes people aware of environmental hazards. The literature regarding hazards suggests that owning a real estate is connected with a higher level of risk perception than renting an apartment (Grothmann and Reusswig 2006; Oasim et al. 2015; Burningham et al. 2008). However, the studies of Kellens et al. (2011) show no such relationship. It is clear that people who own a cellar or those living on the ground floor are more at risk of flooding. However, these residence characteristics do not influence the level of flood risk perception, which was shown by Kellens et al. (2011). It may prove that risk perception does not focus on the value of a real estate and material goods (Kellens et al. 2011). That coincides with the views of Knocke and Kolivras (2007) claiming that people tend to assess hazards in terms of the probability of losing life and not possessions. Furthermore, the relation between the closeness of a hazard and the risk perceived is ambiguous in the literature. It is considered a positive correlation by some-usually people located closer to the source of the hazard (river) display a higher level of risk perception (Miceli et al. 2008; Zhang et al. 2010; O'Neill et al. 2016; Lindell and Hwang 2008) while other researchers, e.g. Colten and Sumpter (2009) and Oasim et al. (2015), regard it as negative; the closer the source, the lower the risk perception due to the incidental nature of flood occurrences. Interestingly, Kellens et al. (2011) observed no such relationship in this matter. The research on flood risk perception regarding the length of residence was also conducted (e.g. Thistlethwaite et al. 2018; Bustillos Ardaya et al. 2007). Both studies show a positive correlation, yet the first one is moderate and the other, to say it straight, weak (Table 2).

Although often neglected, a political and socio-cultural context is a significant aspect in the research on flood risk perception. There are few studies which mention it. They were mostly written in the $1990 \mathrm{~s}$, that is in the period prior to this review. However, it is impossible not to refer to this work discussing factors of flood risk perception. For example, Rohrmann (1994) included the cultural context when distinguishing respondents' various orientation ("technological", "monetary", "ecological" and "feminist"). Individuals with different orientations presented various risk perception. It confirms an opinion that social categories with specified occupational, cultural and political preferences largely differ in terms of the risk assessment. The studies of Kleinhesselink and Rosa (1991) aimed also, among other things, to verify whether the assessment of different types of hazards is determined by a culture through conducting the same research across two culturally diverse countries: Japan and the USA. It was stated that the perception differences observed resulted not from distinct cultural identity but from historical background. However, what 
was spotted at the same time was a phenomenon of 'cross-cultural, cross-gender reversal' which suggests that an influence of gender on risk perception stems from cultural and social factors. This is so because in the risk assessment, Japanese women resembled more American men. The significance of gender is greater in countries where legal and cultural gender differences are stronger. Apart from this, Boholm (1998) reviewing the results of international research drew attention to their variety which may result from distinct geographical, national and cultural contexts of the investigated countries.

Currently, there are few papers discussing a socio-cultural context. For instance, the work of Armas et al. (2015) includes the ethnographic research informing about cultural determinants of the investigated community, the results of which constituted the background of and the supplement to the interpretation of the obtained results of the research on flood risk perception. Działek et al. (2013a, b) drew attention to various historical paths of the investigated area influencing the power of social ties and a type of social capital, which in turn, as was mentioned earlier, stimulate the impact of indirect experience on flood risk perception (Table 2).

Political context in the studies on flood risk perception is mainly touched upon in the aspect of investigating factors influencing preparedness. In this type of work what is sometimes considered is the human sense of responsibility for actions reducing hazards and the trust in authorities and public flood protection means as variables that could influence taking preventive measures. For example, the studies of Bichard and Kazmierczak (2012) as well as Terpstra and Gutteling (2008) reveal a common belief that authorities are primarily accountable for flood protection and thus obliged to release the residents from flood protection responsibility. The investigations of Stojanov et al. (2015) prove that an increase in the proportion of compensation negatively affects the number of undertaken flood preventive means. Bubeck et al. (2012) regard the role of authorities even as an obstacle in taking private mitigating means. According to Birkholz et al. (2014), the level of human sense of responsibility for taking preventive actions is strictly connected with their trust in the effectiveness of "public" preventive means. Wachinger et al. (2013) notices correctly that negative emotions connected with previous experiences reduce trust in authorities and official flood protection means while positive feelings increase it. Both Terpstra (2011) and Hung (2009) in their research state that trust in public flood protection was negatively connected with preparedness and the intention to buy insurance. Grothmann and Reusswig (2006), likewise, wrote that reliance on flood protection was correlated negatively with accepting flood protection means in the past. Thus, what is indicated is the role of public authorities, including the level of trust in them as well as in public protection means, in forming the relation between flood risk perception and preparedness of people in flood endangered areas (Grothmann and Reusswig 2006; Terpstra 2011; Heitz et al. 2009; Terpstra 2009). Trust becomes even more important if an individual knowledge of the hazard is limited (Wachinger et al. 2013; Kellens et al. 2013). Reliance on flood protection means can still cause undesirable side-effects. This is so because persons residing in areas protected by embankments have a false sense of safety which results in undervaluation of the flood risk and a decreased activity connected with preparedness. In this case a lowered perception is a so-called "embankment effect" (Terpstra 2009; Burton and Cutter 2008; Kousky and Kunreuther 2009; Ludy and Kondolf 2012). Moreover, Raska (2015) explains that visible differences in the perception of environmental hazards (including the flood risk) in Western and East-Central Europe are due to diverse cultural, political and social conditions (resulting from historical background) of these countries. Passive attitude of East-Central Europe societies towards the flood risk results from post-communist tradition of those countries, burdened with a strong position of central government bodies. Due to 
the fact that materialistic (material-survival) orientation of values is dominating in those countries (in newly decentralized and liberalized societies), their inhabitants worry to a greater extent and display greater awareness of environmental hazards in comparison with the citizens of Western Europe with post-materialistic orientation (Table 2).

The influence of religion on the perception of and the attitude towards the flood risk is a different issue. This aspect was analysed in the work of Schmuck (2000) who shows that in the investigated Muslim community religion is considered to influence human risk perception (flood is an act of Allah), which results in not taking any actions for preparedness and mitigation of flood hazards (Table 2).

\subsection{Relations between awareness, worry, preparedness and flood risk perception (in general)}

The influence of the awareness of life on the level of worry in a flood risk area is ambiguous. Some people claim that worry depends on being aware of the frequency of certain events occurring (Raaijmakers et al. 2008) and increases dramatically among those aware of their exposure to the flood risk (Bradford et al. 2012). The research of others has not shown any dependency between worry and risk awareness (see Pagneux et al. 2011; Poortinga et al. 2011) (Fig. 1).

There are diverse results as to the influence of worrying and the awareness on preparedness, especially on the application of preventive measures by inhabitants. On the one hand, the majority of works list worry as a direct or indirect motivator for the promotion of preventive behaviours among the people at risk (Raaijmakers et al. 2008; Grothmann and Reusswig 2006; Miceli et al. 2008). The studies of Siegrist and Gutscher (2006, 2008), Takao et al. (2004), Miceli et al. (2008), Zaalberg et al. (2009) as well as Terpstra (2011) have also shown a positive dependence between emotional elements such as fear or worry and the application of mitigating means. However, on the other hand, according to Biernacki et al. (2009), Bradford et al. (2012) and Kreibich (2011), worrying does not increase preparedness. Psychologists indicate that people are unwilling to invest in protection against rarely occurring dangers - this unwillingness is larger than the fear of even a major, although improbable loss (Biernacki et al. 2009). For the above reasons, a notion that

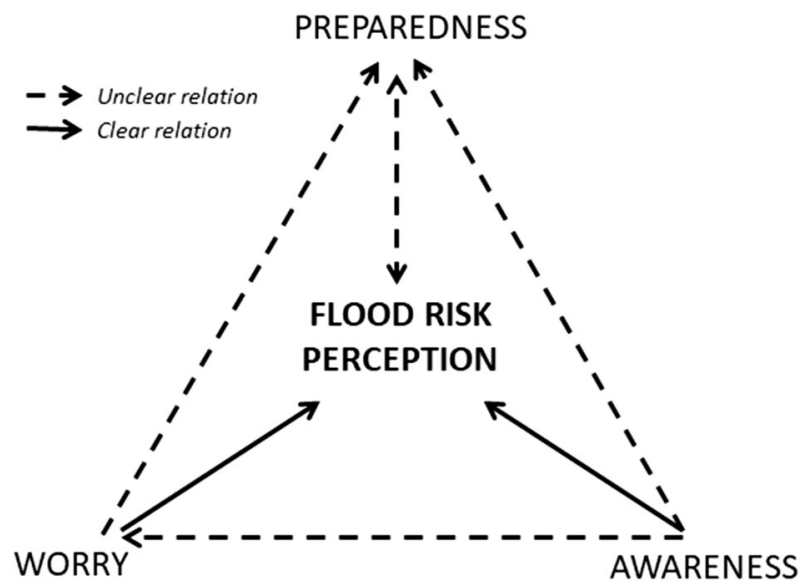

Fig. 1 'Triangle of flood risk perception'-relations between its basic elements 
stimulating the feeling of fear is often recommended to increase risk perception is incorrect (Kievik and Gutteling 2010). In the opinion of Kron (2002) as well as Bubeck et al. (2012), preparedness requires awareness in order to limit the losses. The studies of Bradford et al. (2012) have not confirmed the relation between the awareness of the people located in the area at risk of flooding and the higher level of preparedness (Fig. 1).

Finally, in the relation between the three basic elements of risk perception (awareness, worry and preparedness), two paths of reasoning may be distinguished. According to the first one, awareness can lead to higher levels of worry, and, in consequence, to a higher level of preparedness. A better prepared society will worry less about the risk. The worry stems from the awareness of a high-risk level and the lack of preparedness for it (Raaijmakers et al. 2008). The second, more modern trend of thought believes that awareness and worry do not correlate with a high level of preparedness. Worry does not play a major role in the relationship between awareness and preparedness (Bradford et al. 2012) (Fig. 1).

Discrepancies also concern the meaning of risk perception in taking precautionary actions. For example, in the research of Botzen et al. (2009b), Siegrist and Gutscher (2006), Takao et al. (2004), Thieken et al.(2006), Grothmann and Reusswig (2006), Thieken et al. (2007), Miceli et al. (2008) and Lindell and Hwang (2008) flood risk perception appears to be the most dominating factor stimulating private mitigating behaviours. In this case, people take precautionary measures in order to decrease the high perception of flood risk (Stojanov et al. 2015). Baan and Klijn (2004), Plapp and Werner (2006), Terpstra et al. (2009), Plattner et al. (2006), Duží et al. (2014) and Biernacki et al. (2009) also claim that the perception of risk positively influences the probability of taking preventive steps. However, according to the literary analysis by Bubeck et al. (2012), in reality this relationship is rarely observed in empirical studies (e.g. Kreibich et al. 2005; Siegrist and Gutscher 2006; Takao et al. 2004; Thieken et al. 2007; Miceli et al. 2008; Lindell and Hwang 2008; Thieken et al. 2006; Harries 2008; Thistlethwaite et al. 2018) there have been, statistically, little to no meaningful relations between flood risk perception and taking private mitigating measures. Therefore, flood risk perception is a rather weak independent variable of protective behaviours (Bubeck et al. 2012; Milne et al. 2000). The lack of relationship between the variables may result from the reduction of cognitive dissonance or constitute a reaction to the already applied mitigating means. In reality, a respondent has a smaller risk perception because he or she takes flood reducing measures, which was not considered in the above-mentioned empirical studies. Therefore, as Bubeck et al. (2012) observed, while assessing the relationship between the variables of the perception of risk and mitigating behaviours, the precautionary measures taken need to be controlled. Duží et al. (2014) have similar doubts as to the interpretation of the abovementioned results. Firstly, people may not remember their actions from several years ago or know whether any mitigating steps have been taken before they took residence in their home. Secondly, none of the respondents admitted to removing or limiting the earlier applied measures, which also could have taken place (Duží et al. 2014). In view of the above some studies began to research the relations between flood risk perception and the intention to take private steps mitigating flood (Zaalberg et al. 2009; Botzen et al. 2009b; Botzen and van den Bergh 2012; Terpstra 2011; Thistlethwaite et al. 2018). Contrary to the formerly published results, the studies have shown significant relationship between these variables (Bubeck et al. 2012). Taking this into account, according to Kreibich (2011), flood risk perception is not a crucial factor for taking measures diminishing the risk of flooding — social and economic factors are of greater importance (Fig. 1).

Wachinger et al. (2013) in their literature review indicate three reasons why persons with high-risk perception do not take mitigating means: (1) prospective advantages of 
living near a river seem prevail over potential negative effects, (2) responsibility for action is passed to someone else, e.g. authorities, (3) lack of action stems from minor economic and personal resources. The second argument reveals the significance of the political context and the influence of the policy of authorities and institutions on the relation between flood risk perception and preparedness which was described in subchapter 4.3 herein. The third reason is confirmed by the studies of Zaalberg et al. (2009) and Grothmann and Reusswig (2006) conducted within the Protection Motivation Theory (PMT), which have shown that the assessment of copying capacity stemming from the accessibility of economic and organizational means plays a bigger role in taking protective behaviours than the hazard assessment.

The studies of Bichard and Kazmierczak (2012) as well as Terpstra and Gutteling (2008) confirm the second reason for non-adaptive activities. Their research has shown a common belief that authorities are primarily responsible for flood protection and thus obliged to remove this burden from inhabitants. Stojanov et al. (2015) have proved that a raising percentage of the damages awarded negatively influences the number of the flood protection means applied. Bubeck et al. (2012) discern the role of authorities as an obstacle in taking private mitigating means. Birkholz et al. (2014) claim that the level of the sense of inhabitants' responsibility for taking protective measures is strictly connected with their belief in the effectiveness of "public" protective means. Wachinger et al. (2013) correctly notices that negative feelings related to previous experiences undermine trust in authorities and official flood protection means, whereas positive emotions increase this confidence. Both Terpstra (2011) and Hung (2009) in their works state that trust in public flood protection was negatively connected with preparedness and the intention to buy insurance. Grothmann and Reusswig (2006), likewise, write that confidence in flood protection is negatively correlated with applying flood protection means in the past. Thus, emphasis was put on the role of public authorities including the level of trust in them and in public protective means in forming the relation between flood risk perception and preparedness of people living in flood risk areas. Trust becomes even more important if an individual knowledge of the hazard is poor (Wachinger et al. 2013; Kellens et al. 2013). Confidence in flood protection means can cause undesirable side-effects. This is so because people living in areas protected by embankments have a false sense of safety, which results in the underestimation of the flood risk and limited preparatory measures. In this case a lowered perception is a so-called "embankment effect" (Terpstra 2009; Burton and Cutter 2008; Kousky and Kunreuther 2009; Ludy and Kondolf 2012).

The third reason given by Wachinger et al. (2013) which explains neglecting mitigating means by residents of flood risk areas is confirmed by the studies of Zaalberg et al. (2009) and Grothmann and Reusswig (2006). Conducted within the Protection Motivation Theory (PMT), the research shows that the assessment of copying capacity resulting from the accessibility to economic and organizational resources plays a bigger role in applying protective behaviours than the risk assessment.

In turn, Biernacki et al. (2009) and Aronson (2002) the paradox observed explain as the need to reduce cognitive dissonance, which consists in a subconscious minimization of danger and diminishing the inconsistencies between contradictory information. Cognitive dissonance occurs when people are faced with unpleasant and unavoidable phenomena. A high-risk level in a given place, fears associated with it and unavoidable losses are contrasted with personal gains connected with living in this place. The denial of risk manifests itself, despite high awareness and worry, with the abandonment of protective measures (Biernacki et al. 2009). 


\section{Classification of flood risk perception factors}

The conducted review allowed distinguishing 22 factors most often considered in the research on flood risk perception. Due to their nature, they can be divided into cognitive, behavioural, socio-economic and demographic factors as well as geographical (physical), informational and contextual (cultural, social, religious, political) (Table 3).

Of the unclear picture of the results of the research on flood risk perception the following factors can be distinguished: primary (clearly influencing flood risk perception or particular attributes of this perception), secondary (with an unclear influence) and mediating (often used for the interpretation of research results) (Table 4, Fig. 2). It is easy to notice that direct experience is a certainty, the most often analysed factor in the literature. It performs a significant role in forming flood risk perception. The most difficult part is to determine factors influencing the application of risk reduction means (preparedness) and the level of flood risk perception. A group of factors influencing them unclearly is the largest. In the case of preparedness, the role of the context (the factors describing the general situation) is more debatable in comparison to the other characteristics of risk (i.e. awareness and worry). The literature review conducted has also allowed the exclusion of the influence of certain variables on flood risk perception (Table 4).

Intervening factors serving as a mediator-weakening or strengthening the influence of personal experience of flood on risk perception are the passage of time from the last disaster and the level of trust in flood protection means. In turn, communication networks in the form of media, personal interactions with other people, in other words indirect experience, and a type of social ties as well as social capital are factors that modify the influence of knowledge on the level of risk perception. Religion, the government policy resulting from historical background and concerning the assurance of public protection against flood, the level of trust in authorities and in public protection measures play a significant role of a mediator affecting the relation between flood risk perception and preparedness. On the other hand, the relationship between gender and risk perception is influenced by cultural determinants (Fig. 2). Culture values also affect a level of concern over flood and the awareness of the existence of the hazard. It is easy to notice that the distinguished intervening factors are mainly soft in character.

Wachinger et al. (2013), in turn, emphasised experience of a natural hazard and trust or lack of trust in authorities and experts as primary factors. Media coverage, age, gender,

Table 3 Classification of flood risk perception factors by their nature

\begin{tabular}{ll}
\hline Nature of factors & Factors \\
\hline Cognitive & Worry, direct experience \\
Behavioural & $\begin{array}{l}\text { Preparedness } \\
\text { Socio-economical and } \\
\text { demographical }\end{array}$ \\
$\begin{array}{l}\text { Age, gender, incomes, education, household size (children), home } \\
\text { ownership, cellar ownership }\end{array}$ \\
$\begin{array}{l}\text { Location (hazard), hazard proximity, type of building (living on ground } \\
\text { floor), length of residence } \\
\text { Contextual (cultural, social, } \\
\text { religious, political) }\end{array}$ & $\begin{array}{c}\text { Awareness (knowledge), indirect experience (media) } \\
\text { Culture, religion, history, political system (government policy), social } \\
\text { bonds (type of social capital), trust in government and public } \\
\text { protection measures }\end{array}$ \\
\hline
\end{tabular}


Table 4 Classification of flood risk perception factors by their influence

\begin{tabular}{|c|c|c|c|}
\hline \multirow{2}{*}{$\begin{array}{l}\text { Elements of flood risk } \\
\text { perception }\end{array}$} & \multicolumn{2}{|l|}{ Factors } & \multirow[t]{2}{*}{ Not influence } \\
\hline & Primary & Secondary & \\
\hline Worry & $\begin{array}{l}\text { Direct experience } \\
\text { Education }\end{array}$ & $\begin{array}{l}\text { Awareness } \\
\text { Gender }\end{array}$ & - \\
\hline Preparedness & $\begin{array}{l}\text { Worry } \\
\text { Gender } \\
\text { Household size } \\
\quad \text { (children) } \\
\text { Home ownership } \\
\text { Type of building } \\
\text { Living on ground floor } \\
\text { Length of residence }\end{array}$ & $\begin{array}{l}\text { Worry } \\
\text { Awareness } \\
\text { Direct experience } \\
\text { Risk perception } \\
\text { Knowledge } \\
\text { Age } \\
\text { Incomes } \\
\text { Location (hazard) }\end{array}$ & $\begin{array}{l}\text { Education } \\
\text { Hazard proximity }\end{array}$ \\
\hline Awareness & $\begin{array}{l}\text { Direct experience } \\
\text { Knowledge }\end{array}$ & - & $\begin{array}{l}\text { Education } \\
\text { Incomes } \\
\text { Gender } \\
\text { Age }\end{array}$ \\
\hline Risk perception & $\begin{array}{l}\text { Worry } \\
\text { Awareness } \\
\text { Direct experience } \\
\text { Knowledge } \\
\text { Gender }\end{array}$ & $\begin{array}{l}\text { Hazard proximity } \\
\text { Location (hazard) } \\
\text { Length of } \\
\text { residence } \\
\text { Home ownership } \\
\text { Age } \\
\text { Education } \\
\text { Preparedness }\end{array}$ & $\begin{array}{l}\text { Cellar ownership } \\
\text { Living on ground floor } \\
\text { Incomes } \\
\text { Household size } \\
\text { (children) }\end{array}$ \\
\hline
\end{tabular}

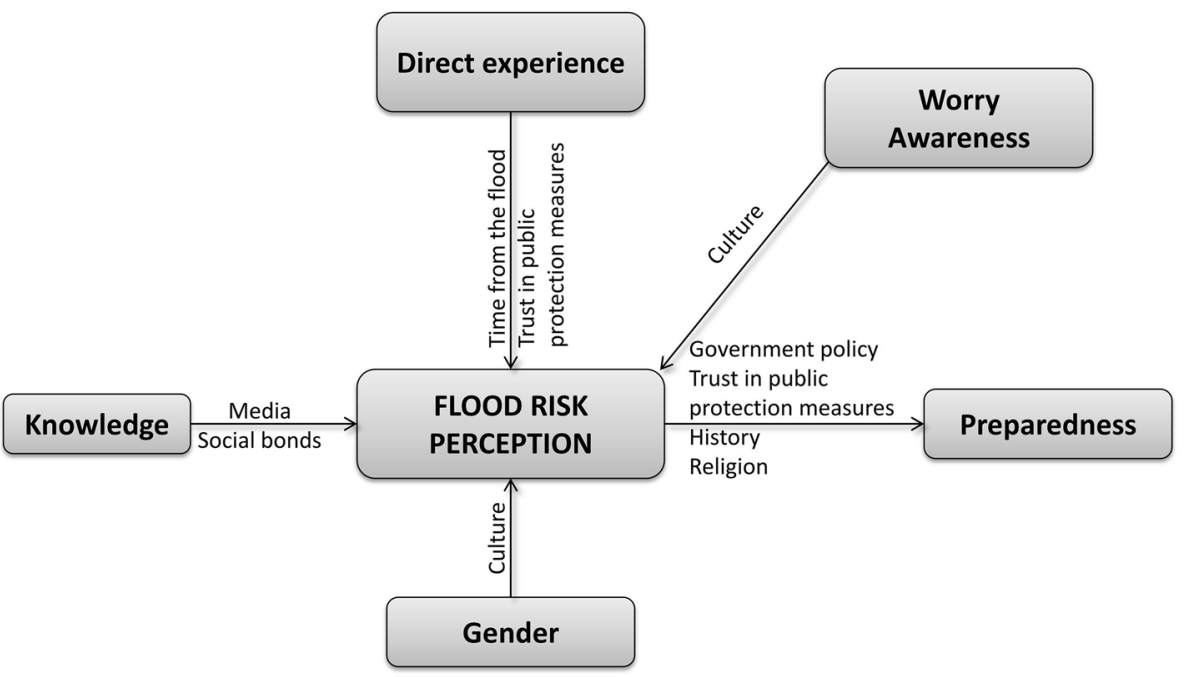

Fig. 2 Intervening factors in the perception of flood risk 
education, income, social status were called intervening factors. Such a division partly overlaps with and partly even excludes from the classification of factors by the type of their influence on flood risk perception suggested in this review. There are possibly two reasons for this. First, Wachinger et al. (2013) focused on the European research results. This review, however, includes empirical work from various continents. Second, Wachinger et al. (2013) analysed risk perception in relation to natural disasters in general, whereas this review analysed it with regard to the flood risk alone.

\section{Conclusions}

This article aims to prepare a list of factors taken into account while studying flood risk perception and classifying them according to the nature and type of influence on flood risk perception, and consequently the formulation of recommendations on the direction of further research in this area based on the analysis of empirical works.

The prepared catalogue of the most frequently repeated factors in the flood risk perception research is not closed. It results from the scope of the empirical research subject to the review. Due to a psychometric approach prevailing in flood risk perception studies, the factors identified are rather hard than soft in nature-they concern variables that can be measured in terms of quantity or be evaluated with the ordinal scale. What is important, the work conveys information about mutual relations between the identified factors of flood risk perception.

The review has shown the complexity of relations between the three attributes of flood risk perception which are worry, awareness and preparedness. Nevertheless, the following regularities can be noticed:

- Worry and awareness in empirical studies express flood risk perception and are often identified with it. In survey research, when asked about the level of flood risk perception, respondents had to answer the question: To what degree are you afraid of flood?, To what degree, in your opinion, are you at risk from flooding? The research results proved unequivocally that worry and awareness determine the level of flood risk perception.

- Preparedness is treated in comparison with worry and awareness as a separate issue in the flood risk perception research. There has been an extensive search for factors that would influence taking preventive measures in relation to the level of flood risk perception.

Taking the above into consideration, a behavioural approach is clearly indicated in the works concerning flood risk perception, because the majority of analysed empirical works seek relations between perception and adapting behaviour alleviating the flood risk and try to determine their predictors. Therefore, among the three elements of flood risk perception analysed in the work, the aspect of preparedness has been analysed in-depth in literature. Only to a slight degree such contextual factors as culture, religion, history or political systems are considered in the research on flood risk perception.

Motivated by numerous aims, orientations and research interests, the current research presents a heterogeneous picture. The impact of particular factors on flood risk perception, reported in literature, is unclear. Some of the research results turned out to be contradictory. This is so because the investigation on perception is conducted by researchers in various fields which results in discrepancy in basic theoretical issues (e.g. the definition of a risk), a different way to draw up a research problem and a variety of applied methods. 
Bubeck et al. (2012) and Kellens et al. (2013) even indicate the lack of theoretical framework in the research on flood risk perception conducted so far. Different research results (of the influence of particular factors on flood risk perception) can also derive from various social determinants, i.e. the study on perception was conducted on communities from different countries with different culture, history or political systems. Another source of separate research results are various measuring scales (the number of respondents) and the character of a community investigated. Urban communities are those most often analysed whereas the studies on flood risk perception concerning rural population are rarely carried out. This is so because cities are affected more severely by flooding than villages. Due to that fact, urban areas are better protected with structural means (especially with embankments) than rural regions. One may infer that a diversified level of structural protection of the investigated areas is another reason for discrepancy in research results. The equivalent circumstances of the research affect the comparability of the results, which was not included in the analysed empirical work. It can all cause various results of the research analysed.

\section{Recommendations}

In this review, the systematization of the current research results allows indicating new trends in studies which can lead to stronger statements on risk perception as a social and psychological phenomenon. In the further research on flood risk perception attention should be paid first of all to secondary factors, which unclearly influence the level of a society's flood risk perception and explain their role in shaping risk perception with the use of, e.g. qualitative methods. The direction of their impact according to the research results is either contradictory or is of minor significance. In the models considering secondary factors, the variances explained are relatively low, indicating noise or the presence of other, immeasurable disturbance variables. The authors of the analysed empirical works used rather traditional sociological research based on questionnaires and structured interviews, whereas only scant attention was paid to qualitative research methods. As Bell and Tobin (2007) accurately noticed, a more extensive application of qualitative methods would help in practical interpretation of statistical dependencies.

Moreover, contrasting research results which occur in the case of secondary factors can serve to detect the role of intervening factors such as political or culture differences. Thus, this question is not properly appreciated in the literature.

Based on the conducted literature review, research areas either undiscovered so far by scholars or insufficiently explored in the field of the analysis of flood risk perception can be indicated. For instance, the notion of flood risk perception by the floodplains residents in relation to such physical-geographical determinants as the section of a river, the season, the level of water in a river or weather conditions and taking into account the last flood could be studied. It could result in the observation of other, new, interesting regularities. The analysed research shows a cross-sectional investigation. The studies on flood risk perception lack a longitudinal research which makes cause and effect inference possible. Therefore, there is a need to revive the flood risk research in order to fully understand how a community perceives the flood risk. The studies on the factors of flood risk perception should be approached in a more holistic manner, in view of socio-cultural and historicalpolitical contexts, referring, e.g. to the conceptions of vulnerability, capacity and resilience. The analysis of the flood risk cannot be limited only to metrical (statistical) data, but it should also include people's social and cultural interpretation of the flood hazard. 
So as to make research on flood risk perception more valuable and applicable for decision-makers responsible for flood risk management, its comparability should be greater. It should be further improved both methodically and theoretically. On the one hand, Kellens et al. (2013) draw attention to the need for a more comprehensive definition, and on the other, Bubeck et al. (2012) are of the opinion that one of the reasons for different research results is various definitions of risk. Qualitative methods should certainly be introduced which would make it possible to identify soft factors underestimated by researchers so far. As can be seen, a scientific approach does not fully answer the question what factors influence flood risk perception at the local level where spatial, culture, political contexts and others overlap.

The flood risk perception factors identified in this review should be emphasised to improve the public flood risk perception - to reduce the nowadays common phenomenon of the underestimation of the risk by society and decrease potential flood-related losses.

Acknowledgements The work was funded by the National Science Centre based on the decision number DEC-2011/03/N/HS4/00436.

Open Access This article is distributed under the terms of the Creative Commons Attribution 4.0 International License (http://creativecommons.org/licenses/by/4.0/), which permits unrestricted use, distribution, and reproduction in any medium, provided you give appropriate credit to the original author(s) and the source, provide a link to the Creative Commons license, and indicate if changes were made.

\section{References}

Armas I, Avram E (2009) Perception of flood risk in Danube Delta, Romania. Nat Hazards 50:269-287

Armas I, Ionescu R, Posner CN (2015) Flood risk perception along the Lower Danube river, Romania. Nat Hazards 79:1913-1931

Aronson E (2002) Człowiek. Istota społeczna. PWN, Warszawa

Baan PJA, Klijn F (2004) Flood risk perception and implications for flood risk management in the Netherlands. Int J River Basin Manag 2:1-10

Barnett J, Breakwell GM (2001) Risk perception and experience: hazard personality profiles and individual differences. Risk Anal 21:171-177

Becker G, Aerts JCJH, Huitema D (2013) Influence of flood risk perception and other factors on riskreducing behaviour: a survey of municipalities along the Rhine. J Flood Risk Manag 7:16-30

Bell HM, Tobin GA (2007) Efficient and effective? The 100-year flood in the communication and perception of flood risk. Environ Hazards 7(4):302-311

Bera MK, Daněk P (2018) The perception of risk in the flood-prone area: a case study from the Czech municipality. Disaster Prev Manag 27(1):2-14

Bichard E, Kazmierczak A (2012) Are homeowners willing to adapt to and mitigate the effects of climate change? Clim Chang 112:633-654

Biernacki W, Bokwa W, Działek J, Padło T (2009) Społeczności lokalne wobec zagrożeń przyrodniczych i klęsk żywiołowych Wydawnictwo Instytut Geografii i Gospodarki Przestrzennej Uniwersytetu Jagiellońskiego, Kraków

Birkholz S, Muro M, Jeffrey P, Smith HM (2014) Rethinking the relationship between flood risk perception and flood management. Sci Total Environ 478:12-20

Boholm A (1998) Comparative studies of risk perception: a review of twenty years of research. J Risk Res $1(2): 135-163$

Botzen WJW, van den Bergh JCJM (2012) Monetary valuation of insurance against flood risk under climate change. Int Econ Rev 53:1005-1026

Botzen WJW, Aerts JCJH, Van Den Bergh JCJM (2009a) Dependence of flood risk perceptions on socioeconomic and objective risk factors. Water Resour Res. https://doi.org/10.1029/2009WR007743

Botzen WJW, Aerts JCJH, van den Bergh JCJM (2009b) Willingness of homeowners to mitigate climate risk through insurance. Ecol Econ 68:2265-2277 
Bradford RA, O’Sullivan JJ, van der Craats IM, Krywkow J, Rotko P, Aaltonen J, Bonaiuto M, De Dominici S, Waylen K, Schelfaut K (2012) Risk perception-issues for flood management in Europe. Nat Hazards Earth Syst Sci 12:2299-2309

Brown JD, Damery SL (2002) Managing flood risk in the UK: towards an integration of social and technical perspectives. Trans Inst Br Geogr 27:412-426

Bubeck P, Botzen WJW, Aerts JCJH (2012) A review of risk perceptions and other factors that influence flood mitigation behavior. Risk Anal 32:1481-1495

Burn DH (1999) Perceptions of flood risk: a case study of the Red River flood of 1997. Water Resour Res $35: 3451-3458$

Burningham K, Fielding J, Thrush D (2008) "It'll never happen to me": understanding public awareness of local flood risk. Disasters 32(2):216-238

Burton C, Cutter S (2008) Levee failures and social vulnerability in the Sacramento-San Joaquin Delta Area. California. Nat Hazards Rev 9(Special issue: Flooding in the Central Valley):136-149

Bustillos Ardaya A, Evers M, Ribbe L (2007) What influences disaster risk perception? Intervention measures, flood and landslide risk perception of the population living in flood risk areas in Rio de Janeiro state, Brazil. Int J Disaster Risk Reduct 25:227-237

Ceobanu C, Grozavu A (2009) Psychosocial effects of the floods. Perception and attitudes. Carpathian J Earth Environ Sci 4:25-38

Chauvin B, Hermand D, Mullet E (2007) Risk perception and personality facets. Risk Anal 27:171-185

Colten CE, Sumpter AR (2009) Social memory and resilience in New Orleans. Nat Hazards 48:355-364

Comănescu L, Nedelea A (2016) Floods and public perception on their effect. Case study: Tecuci plain (Romania), year 2013. Proc Environ Sci. https://doi.org/10.1016/j.proenv.2016.03.024

Cutter SL, Boruff BJ, Shirley WL (2003) Social vulnerability to environmental hazards. Soc Sci Q 84:242-261

De Marchi B (2007) Flood risk management with the public. In: Proceedings of the European symposium on flood risk management research. Istituto di Sociologia Internazionale di Gorizia, pp 153-154

Duží B, Vikhrov D, Kelman I, Stojanov R, Juřička D (2014) Household measures for river flood risk reduction in the Czech Republic. J Flood Risk Manag. https://doi.org/10.1111/jfr3.12132

Działek J, Biernacki W, Bokwa A (2013a) Impact of social capital on local communities' response to floods in southern Poland. In: Neef A, Shaw R (eds) Risks and conflicts: local responses to natural disasters. Community, environment and disaster risk management, vol 14. Bingley, Emereland, pp 195-205

Działek J, Biernacki W, Bokwa A (2013b) Challenges to social capacity building in flood-affected areas of southern Poland. Nat Hazards Earth Syst Sci 13:2555-2566

Działek J, Biernacki W, Bokwa A (2014) Impact of social capital on local communities' response to floods in Southern Poland. In: Neef A, Shaw R (eds) Risks and conflicts: local responses to natural disasters (community, environment and disaster risk management), vol 14. Emerald Group Publishing Limited, Bingley, pp 185-205

Englander T, Farago K, Slovic PA (1986) Comparative analysis of risk perception in Hungary and the United states. Soc Behav 1:55-66

European Insurance and Reinsurance Federation (CEA) (2007) Reducing the social and economic impact of climate change and natural catastrophes: insurance solutions and public-private partnerships. European Insurance and Reinsurance Federation (CEA), Brussels

Fischhoff B, Slovic P, Lichtenstein S, Read S, Combs B (1978) How safe is safe enough-psychometric study of attitudes towards technological risks and benefits. Policy Sci 9(2):127-152

Fitton SL, Moncaster A, Guthrie P (2015) Investigating the social value of the Ripon rivers flood alleviation scheme. J Flood Risk Manag. https://doi.org/10.1111/jfr3.12176

Grothmann T, Reusswig F (2006) People at risk of flooding: why some residents take precautionary action while others do not. Nat Hazards 38:101-120

Harries T (2008) Feeling secure or being secure? Why it can seem better not to protect yourself against a natural hazard. Health Risk Soc 10(5):479-490

Harries T, Penning-Rowsell E (2011) Victim pressure, institutional inertia and climate change adaptation: The case of flood risk. Glob Environ Change 21:188-197

Heijmans A (2001) Vulnerability-a matter of perception. Disaster management working paper 4. Benfield Grey Hazard Research Center, London

Heitz C, Spaeter S, Auzet AV, Glatron S (2009) Local stakeholders' perception of muddy flood risk and implications for management approaches: a case study in Alsace (France). Land Use Policy 26:443-451

Ho C, Shaw D, Lin S, Chiu YC (2008) How do disaster characteristics influence risk perception? Risk Anal 28(3):635-643 
Howe PD (2011) Hurricane preparedness as anticipatory adaptation: a case study of community businesses. Glob Environ Change 21:711-720

Hung HC (2009) The attitude towards flood insurance purchase when respondents' preferences are uncertain: a fuzzy approach. J Risk Res 12(2):239-258

International Commission for the Protection of the Rhine (ICPR) (2002) Non structural flood plain management: measures and their effectiveness. International Commission for the Protection of the Rhine (ICPR), Koblenz

Jaracz P (2001) Promieniowanie jonizujące w środowisku człowieka. Fizyka, skutki radiologiczne, społeczeństwo. Wydawnictwo Uniwersytet Warszawski, Warszawa

Johnson EJ, Tversky A (1983) Affect, generalization, and the perception of risk. J Pers Soc Psychol 45:20-31

Kellens W, Zaalberg R, Neutens T, Vanneuville W, De Maeyer P (2011) An analysis of the public perception of flood risk on the Belgian coast. Risk Anal 31:1055-1068

Kellens W, Terpstra T, Schelfaut K, De Maeyer P (2013) Perception and communication of flood risks: a literature review. Risk Anal 33(1):24-49

Kievik M, Gutteling JM (2010) Yes, we can: motivating Dutch citizens to engage in self-protective behaviors with regard to flood risks. University of Twente, Enschede

King D (2000) You're on our own: community vulnerability and the need for awareness and education for predictable natural disasters. J Conting Crisis Manag 8:223-228

Kleinhesselink RR, Rosa EA (1991) Cognitive representations of risk perceptions: a comparison of Japan and the United States. J Cross Cult Psychol 22:11-28

Knocke ET, Kolivras KN (2007) Flash flood awareness in south west Virginia. Risk Anal 27:155-169

Koks EE, Jongman B, Husby TG, Botzen WJW (2015) Combining hazard, exposure and social vulnerability to provide lessons for flood risk management. Environ Sci Policy 47:42-52

Kousky C, Kunreuther H (2009) Improving flood insurance and flood risk management: insights from St. Louis, Missouri. Res Future RFF DP 09-07

Krasovskaia I, Gottschalk L, Saelthun NR, Berg H (2001) Perception of the risk of flooding: the case of the 1995 flood in Norway. Hydrol Sci J 46:855-868

Kraus NN, Slovic P (1988) Taxonomic analysis of perceived risk: modeling individual and group perceptions within homogenous hazard domains. Risk Anal 8:435-455

Kreibich H (2011) Do perceptions of climate change influence precautionary measures? Int J Clim Change Strateg Manag 2:189-199

Kreibich H, Thieken AH, Petrow T, Müller M, Merz B (2005) Flood loss reduction of private households due to building precautionary measures: lessons learned from the Elbe flood in August 2002. Natl Hazards Earth Syst Sci 5:117-126

Kreibich H, Seifert I, Thieken AH, Lindquist E, Wagner K, Merz B (2011) Recent changes in flood preparedness of private households and businesses in Germany. Reg Environ Change 11:59-71

Kron W (2002) Keynote lecture: flood risk $=$ flood risk $\times$ exposure $\times$ vulnerability. In Wu B, Huang Z, Wang G, Huang G, Fang H and Huang J (eds) Flood defence 2002: proceedings of the 2nd international conference on flood defence. Sci Press, New York, pp 82-97

Kunreuther H (1996) Mitigating disaster losses through insurance. J Risk Uncertain 12:171-187

Lamond JE, Proverbs DG, Hammond FN (2009) Accessibility of flood risk insurance in the UK: confusion, competition and complacency. J Risk Res 12:825-841

Lewis J, Kelman I, Lewis SAV (2011) Is "fear itself" the only thing we have to fear? Explorations of psychology in perceptions of the vulnerability of others. AustJ Disaster Trauma Stud 3:89-104

Lindell MK, Hwang SN (2008) Household's perceived personal risk and responses in a multihazard environment. Risk Anal 28:539-556

Ludy J, Kondolf GM (2012) Flood risk perception on lands 'protected' by 100-year Levees. Nat Hazards. https://doi.org/10.1007/s11069-011-0072-6

Messner F, Meyer V (2006) Flood damage, vulnerability and risk perception—challenges for flood damage research. In: Schanze J, Zeman E, Marsalek J (eds) Flood risk management-hazards, vulnerability and mitigation measures. Nato science series IV. Springer, Cham, pp 149-167

Miceli R, Sotgiu I, Settanni M (2008) Disaster preparedness and perception of flood risk: a study in an alpine valley in Italy. J Environ Psychol 28:164-173

Milne S, Sheeran P, Orbell S (2000) Prediction and intervention in health-related behavior: a meta-analytic review of protection motivation theory. J Appl Soc Psychol 30:106-143

Morgan MG, Fischhoff B, Bostrom A, Atman CJ (2001) Risk communication: a mental models approach. Cambridge University Press, Cambridge

O'Neill E, Brereton F, Shahumyan H, Clinch JP (2016) The impact of perceived flood exposure on floodrisk perception: the role of distance. Risk Anal 36(11):2158-2186 
Oasim S, Khan AN, Shrestha RP, Qasim M (2015) Risk perception of the people in the flood prone Khyber Pukhthunkhwa province of Pakistan. Int J Disaster Risk Reduct 14:373-378

Pagneux E, Gísladóttir G, Jónsdóttir S (2011) Public perception of flood hazard and flood risk in Iceland: a case study in a watershed prone to ice-jam floods. Nat Hazards 58:269-287

Peacock WG, Brody SD, Highfield W (2005) Hurricane risk perceptions among Florida's single family homeowners. Landsc Urb Plan 73:120-135

Plapp T, Werner U (2006) Understanding risk perception from natural hazards: examples from Germany. In: Amman WJ, Dannenmann S, Vulliet L (eds) RISK 21—coping with risks due to natural hazards in the 21st century. Taylor \& Francis Group, London, pp 101-108

Plattner T, Plapp T, Hebel B (2006) Integrating public risk perception into formal natural hazard risk assessment. Nat Hazards Earth Syst Sci 6:471-483

Poortinga W, Bronstering K, Lannon S (2011) Awareness and perceptions of the risks of exposure to indoor radon: a population based approach to evaluate a radon awareness and testing campaign in England and Wales. Risk Anal 31:1800-1812

Poussin J, Botzen WW, Aerts JC (2014) Factors of influence on flood damage mitigation behaviour by households. Environ Sci Policy 40:69-77

Raaijmakers R, Krywkow J, van der Veen A (2008) Flood risk perceptions and spatial multi-criteria analysis: an exploratory research for hazard mitigation. Nat Hazards 46:307-322

Raska P (2015) Flood risk perception in Central-Eastern European members states of the EU: a review. Nat Hazards 79:2163-2179

Renn O (2005) White paper on risk governance. Towards an integrative approach. The International Risk Governance Council, Geneva

Ristic R, Kostadinov S, Abolmasov B, Dragicevic S, Trivan G, Radic B, Trifunovic M, Radosavljevic Z (2012) Torrential floods and town and country planning in Serbia. Nat Hazards Earth Syst Sci $12: 23-35$

Rohrmann B (1994) Risk perception of different societal groups: australian findings and cross-national comparison. Aust J Psychol 46:150-163

Scheuer S, Haase D, Meyer V (2011) Exploring multicriteria flood vulnerability by integrating economic, social and ecological dimensions of flood risk and coping capacity: from a starting point view towards an end point view of vulnerability. Nat Hazards 58(2):731-751

Schmuck H (2000) "An act of Allah": religious explanations for floods in Bangladesh as survival strategy. Int J Mass Emerg Disasters 18(1):85-96

Shen X (2009) Flood risk perception and communication in different cultural contexts-a comparative case study between Wuhan, China and Cologne. Ph.D. dissertation, University of Bonn, Germany

Short JF (1984) The social fabric of risk: toward the social transformation of risk analysis. Am Sociol Rev 49:711-725

Siegrist M, Gutscher H (2006) Flooding risks: a comparison of lay people's perceptions and expert's assessments in Switzerland. Risk Anal 26:971-979

Siegrist M, Gutscher H (2008) Natural hazards and motivation for mitigation behavior: people cannot predict the affect evoked by a severe flood. Risk Anal 28:771-778

Sjöberg L (1996) A discussions of the limitations of the psychometric and cultural theory approaches to risk perception. Radiat Prot Dosim 68:219-225

Sjöberg L (1998) Worry and risk perception. Risk Anal 18:85-93

Slovic P, Finucane ML, Peters E, MacGregor DG (2004) Risk as analysis and risk as feelings: some thoughts about effect, reason, risk and rationality. Risk Anal 24:311-322

Stojanov R, Duží B, Daněk T, Němec D, Procházka D (2015) Adaptation to the impacts of climate extremes in central Europe: a case study in a rural area in the Czech Republic. Sustain 7(9):12758-12786

Takao K, Motoyoshi T, Sato T, Fukuzono T (2004) Factors determining residents' preparedness for floods in modern megalopolises: the case of the Tokai flood disaster in Japan. J Risk Res 7:775-787

Terpstra T (2009) Flood preparedness: thoughts, feelings and intentions of the Dutch public. Thesis, University of Twente, Twente

Terpstra T (2011) Emotions, trust and perceived risk: affective and cognitive routes to flood preparedness behavior. Risk Anal 31:1658-1675

Terpstra T, Gutteling JM (2008) Households' perceived responsibilities in flood risk management in the Netherlands. Int J Water Resour Dev 24:555-565

Terpstra T, Lindell MK, Gutteling JM (2009) Does communicating (flood) risk affect (flood) risk perceptions? Results of a quasi experimental study. Risk Anal 29:1141-1155

Thieken AH, Petrow T, Kreibich H, Merz B (2006) Insurability and mitigation of flood losses in private households in Germany. Risk Anal 26:383-395 
Thieken AH, Kreibich H, Muller M, Merz B (2007) Coping with floods: preparedness, response and recovery of flood-affected residents in Germany in 2002. Hydrol Sci J 52:1016-1037

Thistlethwaite J, Henstra D, Brown C, Scott D (2018) How flood experience and risk perception influences protective actions and behaviours among Canadian homeowners. Environ Manag 61:197-208

Tobin GA, Montz B (1997) Natural hazards: explanation and integration. The Guilford Press, New York

United Nations Office for Disaster Risk Reduction (UNISDR) (2005) United Nations international strategy for disaster risk reduction, Hyogo framework for 2005-2015: building the resilience of nations and communities to disasters

van der Veen A, Logtmeijer CJJ (2005) Economic hotspots: visualising vulnerability to flooding. Nat Hazards 36:65-80

Wachinger G, Renn O, Begg C, Kuhlicke C (2013) The risk perception paradox- implications for governance and communication of natural hazards. Risk Anal 33(6):1049-1065

Werritty A, Houston D, Ball T, Tavendale A, Black A (2007) Exploring the social impacts of flood risk and flooding in Scotland. Scottish Executive Social Research, Edinburgh

Zaalberg R, Midden C, Meijnders A, McCalley T (2009) Prevention, adaptation, and threat denial: flooding experiences in the Netherlands. Risk Anal 29:1759-1778

Zhang Y, Hwang SN, Lindell MK (2010) Hazard proximity or risk perception? Evaluating effects of natural and technological hazards on housing values. Environ Behav 42(5):597-624 